University of Wollongong

Research Online

Faculty of Informatics - Papers (Archive)

Faculty of Engineering and Information

Sciences

November 2006

\title{
Sector Driven Variations on E-commerce Adoption Barriers in Regional Small Businesses: An Australian Study
}

Robert MacGregor

University of Wollongong, rmacgreg@uow.edu.au

L. Vrazalic

University of Wollongong in Dubai, lejla@uow.edu.au

Follow this and additional works at: https://ro.uow.edu.au/infopapers

Part of the Physical Sciences and Mathematics Commons

\section{Recommended Citation}

MacGregor, Robert and Vrazalic, L.: Sector Driven Variations on E-commerce Adoption Barriers in Regional Small Businesses: An Australian Study 2006.

https://ro.uow.edu.au/infopapers/535

Research Online is the open access institutional repository for the University of Wollongong. For further information contact the UOW Library: research-pubs@uow.edu.au 


\title{
Sector Driven Variations on E-commerce Adoption Barriers in Regional Small Businesses: An Australian Study
}

\author{
Abstract \\ Despite being a described as a "business enabling technology", e-commerce has not been embraced by \\ the small businesses sector to the extent that it has in larger organisations. This situation has arisen due \\ to a number of e-commerce barriers faced by small businesses. A number of studies have examined \\ these barriers, however, our understanding of their role in e-commerce adoption remains somewhat \\ superficial. This paper presents the results of a large study of Australian small businesses located in a \\ regional area which explored the relationship between business sectors (industrial, retail and service) and \\ e-commerce barriers. The results indicate that service sector small businesses are more discerning about \\ e-commerce barriers than their industrial and retail counterparts. The study has implications for e- \\ commerce adoption initiatives by government organisations.

\section{Disciplines} \\ Physical Sciences and Mathematics

\section{Publication Details} \\ This paper was originally published as: MacGregor, R \& Vrazalic, L, Sector Driven Variations on E- \\ commerce Adoption Barriers in Regional Small Businesses: An Australian Study, Innovations in \\ Information Technology 2006, Dubai, United Arab Emirates, $19-21$ November 2006, 1-5. Copyright IEEE \\ 2006.
}




\section{Sector Driven Variations on E-commerce Adoption Barriers in Regional Small Businesses: An Australian Study}

\author{
Robert MacGregor \\ University of Wollongong \\ rmacgreg@uow.edu.au
}

\author{
Lejla Vrazalic \\ University of Wollongong in Dubai \\ LejlaVrazalic@uowdubai.ac.ae
}

\begin{abstract}
Despite being a described as a "business enabling technology", e-commerce has not been embraced by the small businesses sector to the extent that it has in larger organisations. This situation has arisen due to a number of e-commerce barriers faced by small businesses. A number of studies have examined these barriers, however, our understanding of their role in ecommerce adoption remains somewhat superficial. This paper presents the results of a large study of Australian small businesses located in a regional area which explored the relationship between business sectors (industrial, retail and service) and e-commerce barriers. The results indicate that service sector small businesses are more discerning about e-commerce barriers than their industrial and retail counterparts. The study has implications for e-commerce adoption initiatives by government organisations.
\end{abstract}

\section{Introduction}

It has long been recognized that e-commerce technology has the potential to become a major source of competitive advantage to small businesses because it is a cost effective way of reaching customers globally and competing on par with larger counterparts. Several studies $[1,2]$ have noted that despite government initiatives aimed at facilitating e-commerce adoption by small businesses, it is mainly the larger businesses that have reaped the benefits of this technology. Indeed, the rate of e-commerce adoption in the small business sector has remained relatively low. This sluggish pace of e-commerce diffusion into small businesses has been attributed to various barriers or impediments that are faced by these organizations.

A number of different e-commerce adoption barriers have been documented in research studies, including the high costs associated with e-commerce, lack of technical resources and expertise to implement e-commerce, the complexity of e-commerce technology and the difficulty of measuring the return on investment. It is unclear, however, whether these barriers are applicable to small businesses in regional areas, nor has there been an attempt to examine the impact of business characteristics, and specifically the sector in which the small business operates, on ecommerce barriers. As a result, our understanding of what needs to be done to assist small businesses overcome e-commerce adoption barriers is fragmented and incomplete, potentially rendering government initiatives ineffective.

The aim of this paper is to examine whether the grouping of barriers to e-commerce adoption differ across differing business sectors within the regional small business spectrum. The paper begins by examining the nature of small businesses. Small businesses in regional areas and their role are then discussed. This is followed by a literature review of ecommerce adoption barriers that were used to develop a survey instrument for a study of small businesses in regional Australia. The paper then presents a factor analysis study to determine whether there are differences in the groupings e-commerce barriers, depending upon the business sector involved. A discussion of the results follows.

\section{Small Business}

Small businesses are defined as organisations that employ less than fifty people [3]. Yet despite their size, small businesses are seen as significant contributors to the prosperity of national economies. The Australian government recognises that small businesses are a "powerhouse" of economic potential, whose employees account for almost five million members of the workforce [4] making them a major source of jobs. In recent years, small businesses have faced a number of challenges. With the establishment of Free Trade Agreements between countries worldwide, small businesses are increasingly competing in global 
markets. This has been made possible by the advent of e-commerce technology.

Small businesses are not simply scaled down versions of large businesses [5]. Although size is a major distinguishing factor, small businesses have a number of other unique features that set them apart from large businesses. There have been various studies carried out in order to isolate these features $[6,7,8]$ which can be classified as internal (related to management, decision-making and planning processes within the organisation, and the availability of resources) and external (related to the market and the external environment, risk taking and uncertainty).

\subsection{Small Businesses in Regional Areas}

Small businesses located in regional areas are affected by circumstances inherent to their location. Regional areas are defined as geographical areas located outside metropolitan centres and major cities. The Australian Bureau of Statistics [3] classifies regional areas into inner and outer regions, remote and very remote areas. Rather than remote and rural areas, the research presented in this paper focuses on inner and outer regional areas (which are more urbanised).

Regional areas are of particular interest to governments because they are characterised by high unemployment rates [9], a shortage of skilled people, limited access to resources and a lack of infrastructure [10]. Yet, at the same time, businesses located in regional areas in Australia contribute $50 \%$ of the national export income (ibid). This implies that small businesses have the potential to play a major role in developing regional areas. Small businesses have been earmarked as playing an important role in promoting growth because they are seen as a key source of jobs and employment prospects [9,10]. To encourage growth and development in regional areas, government organisations have been heavily promoting the adoption of information and communication technology (ICT) by small businesses. Despite these programs and initiatives, the rate of e-commerce adoption in small businesses has been low. The reasons for this are diverse, however they are generally categorised as barriers to e-commerce adoption.

\section{E-Commerce Adoption Barriers}

Research shows that it is mostly larger businesses that have benefited from e-commerce adoption [1] with small businesses showing a much slower pace of adoption. The reasons for this are diverse and have been examined in various studies as inhibitors or barriers that prevent small businesses from adopting and, subsequently fully reaping e-commerce benefits.

Hadjimanolis [11], in a study of e-commerce adoption by small businesses in Cyprus, classified these barriers into two types: internal and external. External barriers could be further categorised into supply barriers (difficulties obtaining finance and technical information), demand barriers (e-commerce not fitting with products/services or the way clients did business) and environmental barriers (security concerns). Internal barriers were further subdivided into resource barriers (lack of management and technical expertise) and system barriers (e-commerce not fitting with the current business practices).

While research examining the inhibitors to ecommerce adoption in small businesses has identified a large number of barriers that prevent then from implementing e-commerce, there has not been any attempt to find out whether these barriers affect regional small businesses. Furthermore, our current understanding of e-commerce adoption barriers does not indicate whether business characteristics such as the business sector, have any impact. Without having a clear awareness of the issues that affect e-commerce adoption in small businesses, government initiatives may prove to be ineffective and poorly targeted.

\section{E-Commerce and the Business Sector}

There have been several studies undertaken to examine the relationship between business characteristics and e-commerce adoption in small businesses. These studies have noted that because small businesses are diverse in terms of business size and sector the results are not generalisable across the entire small business sector.

Matlay [12] showed that the business sector was significantly associated with e-commerce adoption. His study showed that the same results were achievable despite varying geographic spread or market focus. Riquelme [1], in a study of 75 Chinese small businesses found that those involved in the service sector tended to adopt e-commerce far more than their manufacturing counterparts.

Other recent studies [13] have also produced findings that indicate that differing business sectors adopt e-commerce and report differing benefits from that adoption, in the small business sector.

Our aim was to take these results a step further and examine whether the business sector was relevant to ecommerce adoption barriers specifically and in regional areas where these barriers may appear to be more prevalent. 


\section{Methodology}

Ten of the most commonly occurring barriers to ecommerce adoption in Table 2 were identified from the literature. A series of six in-depth interviews with regional small businesses in Australia was undertaken to determine whether the barriers were applicable and complete. All of the identified barriers were found to applicable and no additional barriers were forthcoming. Based on the six in-depth interviews, a survey instrument was developed to collect data about ecommerce adoption barriers (amongst other things). Respondents who had not adopted e-commerce were asked to rate the importance of each barrier to their decision not to adopt e-commerce (as shown below) using a standard 5 point Likert scale. The Likert scale responses were assumed to posses the characteristics of an interval measurement scale for data analysis purposes.

\begin{tabular}{|c|c|c|c|c|c|c|}
\hline \multicolumn{7}{|c|}{$\begin{array}{l}\text { 23. This question relates to the reasons why your organisation is not using e-commerce. B } \\
\text { indicating possible reasons. Based on your opinion, please rank each statement on a scale } \\
\text { important it was to your decision NOT to use e-commerce, as follows: } \\
1 \text { = the reason was very unimportant to your decision not to use e-commerce } \\
2 \text { = the reason was unimportant to your decision not to use e-commerce } \\
3=\text { the reason was neither unimportant nor important to your decision not to use e-commerce } \\
4=\text { the reason was important to your decision not to use e-commerce } \\
5=\text { the reason was very important to your decision not to use e-commerce }\end{array}$} \\
\hline No. & Our organisation does not use e-commerce because: & \multicolumn{5}{|c|}{ Rating } \\
\hline 1 & E-commerce is not suited to our products/ services. & 1 & 2 & 3 & & \\
\hline 2 & E-commerce is not suited to our way of doing business. & 1 & 2 & 3 & 4 & \\
\hline 3 & E-commerce is not suited to the ways our clients (customers/ suppliers) do business. & 1 & 2 & 3 & 4 & \\
\hline 4 & E-commerce does not offer any advantages to our organisation. & 1 & 2 & 3 & 4 & \\
\hline 5 & We do not have the technical knowledge to implement e-commerce. & 1 & 2 & 3 & 4 & \\
\hline 6 & E-commerce is too complicated to implement. & 1 & 2 & 3 & 4 & \\
\hline 7 & E-commerce is not secure. & 1 & 2 & 3 & 4 & \\
\hline 8 & The financial investment required to implement e-commerce is too high for us. & 1 & 2 & 3 & & \\
\hline 9 & We do not have time $\mathrm{t}$ & 1 & & 3 & & \\
\hline 10 & It is difficult to choose the most suitable e-commerce standard (too many options). & 1 & 2 & 3 & 4 & \\
\hline
\end{tabular}

The study was conceived primarily as exploratory in nature. To qualify as a regional area, the following criteria was applied: the location must be an urban regional area; a viable government-initiated Chamber of Commerce must exist and be well patronised by the small business community; the location should have a full range of educational facilities; the business community must represent a cross-section of business ages, sizes, sectors and market foci.

The location chosen was the greater Wollongong area, in New South Wales (Australia), and 250 small businesses were surveyed by telephone. The survey was administered by telephone to ensure an appropriate response rate.

\section{Results and Findings}

Responses were obtained from 164 small business organisations giving a response rate of $65.6 \%$ which is consistent with phone surveys. The total number nonadopters was 139 , representing $84.4 \%$ of the valid responses. The responses of the non-adopters were examined in detail and it was determined that all 139 responded to every statement in the question regarding barriers to e-commerce adoption. The responses formed the basis for the statistical analysis carried out using SPSS. An inspection of the frequencies indicated that the full range of the scale was utilised by respondents. The data was subdivided into three business sector groupings: industrial, service and retail. The correlations between the barriers were examined for each of the three business groups (correlation matrices are available from the authors on request).

An examination of the correlation matrices suggested the use of factor analysis to investigate any separate underlying factors and to reduce the redundancy of certain barriers indicated in the Correlation Matrices. The results of Kaiser-MeyerOlkin MSA (.685 for service and .790 for retail) and Bartlett's Test of Sphericity $\left(\chi^{2}=238.21, p=.000\right.$ for service and $\chi^{2}=241.72, p=.000$ for retail) indicated that the data set satisfied the assumptions for factorability. The matrix for the industrial respondents was not positive definite. Principle Components Analysis was chosen as the method of extraction in order to account for maximum variance in the data using a minimum number of factors. For the industrial and retail respondents, a two-factor solution was extracted with Eigenvalues of 6.801 and 1.676 for industrial and 3.251 and 3.142 for retail. For the 
service sector a three factor solution was extracted with Eigenvalues of $3.224,2.763$ and 1.166. These were supported by an inspection of the Scree Plots. These two factors accounted for $84.761 \%$ of the total variance in industrial, $71.519 \%$ of the total variance in service and $63.929 \%$ in retail sectors.

For the industrial and retail sectors, the two resulting components were rotated using the Varimax procedure and a simple structure was achieved as shown in the Rotated Component Matrix in Table 1. Six barriers loaded highly on the first component. These barriers were related to the complexity of implementation techniques, range of e-commerce options, high investments and the lack of technical knowledge and time. This component has been termed the "Too Difficult" factor. The barriers highly loaded on the second component are termed the "Unsuitable" factor and are related to the suitability of e-commerce to the respondent's business, including the extent to which e-commerce matched the businesses products/services, the way of doing business, their client's way of doing business and the lack of advantages offered by e-commerce implementation.
These two factors are independent and uncorrelated, as an orthogonal rotation procedure was used.

For the service sector the three resulting components were rotated using the Varimax procedure and a simple structure was achieved (ref Table 1). Four barriers loaded highly on the first component. These barriers were related to the complexity of implementation techniques, range of e-commerce options, high investments and the lack of technical knowledge and time. This component has been termed the "Too Difficult" factor. Four barriers loaded on the second component, termed the "Unsuitable" factor and are related to the suitability of e-commerce to the respondent's business, including the extent to which ecommerce matched the businesses products/services, the organisation's way of doing business, their client's way of doing business and the lack of advantages offered by e-commerce implementation. Two barriers loaded onto the final factor, termed "Time and Choice". These three factors are independent and uncorrelated, as an orthogonal rotation procedure was used.

Table 1: Rotated Component Matrix

\begin{tabular}{|c|c|c|c|c|c|c|c|}
\hline & \multicolumn{2}{|c|}{ Industrial } & \multicolumn{2}{|c|}{ Retail } & \multicolumn{3}{|c|}{ Service } \\
\hline $\begin{array}{c}\text { Barrier } \\
\text { No. }\end{array}$ & $\begin{array}{c}\text { Too } \\
\text { Difficult }\end{array}$ & Unsuitable & $\begin{array}{c}\text { Too } \\
\text { Difficult }\end{array}$ & Unsuitable & $\begin{array}{c}\text { Too } \\
\text { Difficult }\end{array}$ & Unsuitable & $\begin{array}{l}\text { Time \& } \\
\text { Choice }\end{array}$ \\
\hline 1 & & .934 & & .892 & & .897 & \\
\hline 2 & & .950 & & .935 & & .833 & \\
\hline 3 & & .957 & & .882 & & .884 & \\
\hline 4 & & .934 & & .833 & & .783 & \\
\hline 5 & .678 & & .766 & & .722 & & \\
\hline 6 & .700 & & .813 & & .914 & & \\
\hline 7 & .550 & & .684 & & .676 & & \\
\hline 8 & .955 & & .621 & & .746 & & \\
\hline 9 & .879 & & .722 & & & & .859 \\
\hline 10 & .774 & & .695 & & & & .876 \\
\hline
\end{tabular}

\section{Discussion}

The aim of this study was to examine the factors underlying barriers to e-commerce adoption in regional small businesses in Australia and to determine whether these differed depending upon the business sector being examined. As can be seen in Table 1, small businesses in two of the sectors (retail and industrial) loaded their barriers across two factors, which we have termed "Too Difficult" and "Unsuitable". The service sector, by comparison loaded barriers to e-commerce adoption across three different factors, termed "Too Difficult", "Unsuitable" and "Time and Choice". In all three sectors, the barriers e-commerce related to ecommerce not being suited to products/services, ways of doing business and clients, and e-commerce not offering any advantages to the organisation were loaded onto the "Unsuitable" factor and in all cases this factor had the highest priority amongst the owner/manager respondents.

In all three cases, four barriers loaded onto the factor termed "Too Difficult". While the barriers related to time and too many options also loaded onto the "Too Difficult" factor for the retail and industrial respondents, the service respondents considered this a separate factor which we have termed "Time and Choice". It is interesting to note, however, that small business respondents across all three sectors rated the unsuitability of e-commerce as a higher priority barrier 
than the others, suggesting that other barriers are viewed as being less critical and easier to overcome.

The results of this study are significant in several ways. The analysis has shown that ten of the most common barriers to e-commerce adoption can be grouped in relation to two or three main factors, depending on the business sector the small business operates in. This gives researchers a powerful explanatory tool because it reduces the "noise" in the data. The Rotated Component Matrix also enables the prediction of the scores of each individual barrier based on the score of the two (or three) other factors, and vice versa. This has implications for research into e-commerce barriers. Whereas before researchers have identified various, this is the first time a study has shown that certain barriers are correlated and can be logically grouped according to two or three factors. Perhaps even more significant is the fact that differences appear to exist between different sectors of the regional small business spectrum. This raises questions concerning the 'one size fits all' policies of many government bodies concerned with e-commerce adoption in small businesses and highlights to need for developing different e-commerce implementation strategies for different business sectors. Finally, the study presented here appears to support previous research which shows that the business sector does have an impact on e-commerce adoption in small businesses.

\section{Conclusion and Limitations}

The primary aim of this paper was to determine whether differing sectors of the regional small business spectrum in Australia gave rise to differing approaches to grouping barriers to e-commerce. Results showed that while the retail and industrial sectors appear to regard the grouping of barriers the same way, the service sector regards certain barriers as distinct and different to the other groups. The results also show that in all three cases, the technical difficulties surrounding e-commerce adoption appear to be of higher priority than those that might be considered more organisational in nature. This would suggest that any initiatives to promote e-commerce adoption in small businesses located in regional areas, must take into account the business sector and respond accordingly. It should be noted that this study has several limitations. The choice of variables selected for the study is somewhat problematic because of the complex nature of adoption barriers which change over time. This study was carried out in an Australian regional area. The results cannot necessarily be generalised to similar regional areas in other countries. Finally, this is a quantitative study, and qualitative research is required to gain a better understanding of the key issues.

\section{References}

[1] Riquelme, H. (2002) Commercial Internet adoption in China: comparing the experience of small, medium and large businesses, Internet Research: Electronic Networking Applications and Policy, 12(3), 276-286.

[2] Magnusson, M. (2001) E-commerce in small businesses focusing on adoption and implementation, Proceedings of the $I^{\text {st }}$ Nordic Workshop on Electronic Commerce, Sweden. [3] ABS (2001) URL: www.abs.gov.au, (Dec 10, 2003). [4] NOIE (2002) e-Business for Small Business, www.noie. gov.au/projects/ebusiness/Advancing/SME, (Dec 10, 2003).

[5] Wynarczyk, P., Watson, R., Storey, D.J., Short, H. \& Keasey, K. (1993) The Managerial Labour Market in Small and Medium Sized Enterprises, Routledge, London.

[6] Bunker, D.J. \& MacGregor, R.C. (2000) Successful Geneeration of Information Technology (IT) Requirements for Small/Medium Enterprises (SME's) - Cases from Regional Australia, Proceedings of SMEs in a Global Economy, Australia, 72-84.

[7] Tetteh, E. \& Burn, J. (2001) Global Strategies for SMEbusiness: Applying the SMALL Framework, Logistics Information Management, 14(1/2), 171-180.

[8] Miller, N.L. \& Besser, T.L. (2000) The Importance of Community Values in Small Business Strategy Formation: Evidence from Rural Iowa, Journal of Small Business Management, 38(1), 68-85.

[9] Larsson, E., Hedelin, L. \& Gärling, T. (2003) Influence of Expert Advice on Expansion Goals of Small Businesses in Rural Sweden, Journal of Small Business Management, 41(2), 205-212.

[10] Keniry, J., Blums, A., Notter, E., Radford, E. \& Thomson, S. (2003) Regional Business - A Plan for Action, Department of Transport and Regional Services, www.rbda.gov.au/action_plan, (Dec 13, 2003).

[11] Hadjimonolis, A. (1999) Barriers to Innovation for SMEs in a Small Less Developed Country (Cyprus), Technovation, 19(9), 561-570.

[12] Matlay, H. (2000) Training in the Small Business Sector of the British Economy, in Carter, S. \& Jones, D. (eds) Enterprise and Small Business: Principles, Policy and Practice, Addison Wesley Longman, London.

[13] MacGregor, R.C., Vrazalic, L., Carlsson, S., Bunker, D.J. \& Magnusson, M. (2002) The Impact of Business Size and Business Type on Small Business Investment in Electronic Commerce: A study of Swedish Small businesses, Australian Journal of Information Systems, 9(2), 31-39. 